Pacific Journal of Mathematics

THE QUOTIENT ALGEBRA OF A FINITE YON NEUMANN 


\title{
THE QUOTIENT ALGEBRA OF A FINITE VON NEUMANN ALGEBRA
}

\author{
MASAMICHI TAKESAKI
}

We will prove the following: Let $M$ be a finite von Neumann algebra with center $Z$ and $A$ a von Neumann subalgebra of $Z$. Let $\Omega$ be the spectrum space of $A$ and identify $A$ with $C(\Omega)$. Let $\varepsilon$ be a $\sigma$-weakly continuous linear map of $M$ onto $A$ such that $\varepsilon\left(x^{*} x\right)=\varepsilon\left(x x^{*}\right) \geqq 0$ for every $x \in M, \varepsilon(a x)=a \varepsilon(x)$ for every $a \in A$ and $x \in M, \varepsilon(1)=1$ and $\varepsilon\left(x^{*} x\right) \neq 0$ for every nonzero $x \in M$. For each $\omega \in \Omega$, let $\mathfrak{m}_{\omega}$ denote the set of all $x \in M$ with $\varepsilon\left(x^{*} x\right)(\omega)=0$. Then $\mathfrak{m}_{\omega}$ is a closed ideal and the quotient $C^{*}$-algebla $M / \mathfrak{m}_{\omega}$ is a finite von Neumann algebra. Furthermore, if $\pi_{\omega}$ denote the canonical homomorphism of $M$ onto $M / \mathfrak{m}_{\omega}$, then $\pi_{\omega}(N)$ is a von Neumann subalgebra of $M / \mathrm{m}_{\omega}$ for every von Neumann subalgebra $N$ containing $A$.

In [8], [3] and [5] it was shown that the quotient $C^{*}$-algebra of a finite von Neumann algebra by any maximal ideal is actually a finite factor. This led us to the algebraic reduction theory for finite von Neumann algebras, which is free from the separability restriction in the direct integral reduction theory. In this paper we will show that the above result still holds for certain ideals, not necessarily maximal. Namely, we will give a straightforward proof for the following.

THEOREM. Let $M$ be a finite von Neumann algebra with center $Z$ and $A$ a von Neumann subalgebra of $Z$. Let $\Omega$ be spectrum space of $A$ and identify $A$ with $C(\Omega)$. Let $\varepsilon$ be a $\sigma$-weakly continuous linear map of $M$ onto $A$ such that $\varepsilon\left(x^{*} x\right)=\varepsilon\left(x x^{*}\right) \geqq 0$ for every $x \in M, \varepsilon(a x)=a \varepsilon(x)$ for every $a \in A$ and $x \in M, \varepsilon(1)=1$ and $\varepsilon\left(x^{*} x\right) \neq 0$ for every nonzero $x \in M$. For each $\omega \in \Omega$, let $\mathfrak{n}_{\omega}$ denote the set of all $x \in M$ with $\varepsilon\left(x^{*} x\right)(\omega)=0$. Then $\mathfrak{m}_{\omega}$ is a closed ideal and the quotient $C^{*}$-algebra $M / \mathfrak{m}_{\omega}$ is a finite von Neumann algebra. Furthermore, if $\pi_{\omega}$ denote the canonical homomorphism of $M$ onto $M / \mathfrak{m}_{\omega}$, then $\pi_{\omega}(N)$ is a von Neumann subalgebra of $M / \mathfrak{m}_{\omega}$ for every von Neumann subalgebra $N$ containing $A$.

Before going into the proof, we observe that there exists such a map $\varepsilon$ if $Z$ is $\sigma$-finite. Since $M$ has the $\xi$-operation, it suffices to show that there exists a $\sigma$-weakly continuous faithful projection of norm one from $Z$ onto $A$. If $Z$ is $\sigma$-finite, then $Z$ admits a faithful normal state $\varphi$. Considering the cyclic representation of $Z$ induced by $\varphi$, we 
may assume that $Z$ acts on a Hilbert space $\mathscr{H}$ containing a vector $\xi_{0}$ such that $\left(x \xi_{0} \mid \xi_{0}\right)=\varphi(x), x \in Z$. Let $e$ be the projection of $\mathscr{H}$ onto $\left[A \xi_{0}\right]$. Then $e$ is an abelian projection in $A^{\prime}$ with central support 1. Note that the center of $A^{\prime}$ is $A$ itself. Then there exists an isomorphism $\theta$ of $e A^{\prime} e$ onto $A$ such that $\theta(x e)=x$ for every $x \in A$ because $A$ is the center of $A^{\prime}$. Put $\varepsilon_{Z}(x)=\theta(e x e)$ for every $x \in Z$. Since $e$ is not orthogonal to any nonzero projection in $Z, \varepsilon_{Z}$ has the required properties. As the composed map of this $\varepsilon_{Z}$ and the operation in $M$, we get a desired map $\varepsilon$. Hence, the situation in the theorem is always presented for any von Neumann subalgebra $A$ of $Z$ if $Z$ is $\sigma$-finite.

The proof of theorem. We will prove the assertion for the subalgebra $N$ which implies immediately the former assertion.

Let $\tau_{\omega}(x)=\varepsilon(x)(\omega), x \in M$. Then $\tau_{\omega}$ is a finite trace of $M$ with the left kernel $\mathfrak{n}_{\omega}$. Let $\left\{\pi, \mathscr{Z}, \xi_{0}\right\}$ be the cyclic representation of $M$ induced by $\tau_{\omega}$. Since $\pi$ has the kernel $n_{\omega}$, $\pi$ induces a faithful representation $\tilde{\pi}$ of the $C^{*}$-algebra $M / \mathfrak{m}_{\omega}$. Since $\tilde{\pi} \circ \pi_{\omega}(N)=\pi(N)$, it suffices to show that $\pi(N)$ is a von Neumann algebra. Since the functional $\tau_{\omega}(x)=\left(x \xi_{0} \mid \xi_{0}\right), x \in \pi(M)^{\prime \prime}$, is a faithful trace on the von Neumann algebra $\pi(M)^{\prime \prime}, \xi_{0}$ is a cyclic and separating for $\pi(M)^{\prime \prime}$. Let $S_{N}$ denote the unit ball of $N$. Then by Kaplansky's density theorem $\pi\left(S_{N}\right)$ is strongly dense in the unit ball $S_{\widetilde{N}}$ of the von Neumann algebra $\widetilde{N}=\pi(N)^{\prime \prime}$ generated by $\pi(N)$. Since the map $x \in \pi(M)^{\prime \prime} \rightarrow x \xi_{0}$ is injective, if $\pi\left(S_{N}\right) \xi_{0}=S_{\widetilde{N}} \xi_{0}$, then we have $\pi\left(S_{N}\right)=$ $S_{\tilde{N}}$; hence $\widetilde{N}=\pi(N)$.

Therefore, we shall prove that $\pi\left(S_{N}\right) \xi_{0}$ is complete. Let $\left\{x_{n}\right\}$ be a sequence in $S_{N}$ such that

$$
\lim _{n, m \rightarrow \infty}\left\|\pi\left(x_{n}\right) \xi_{0}-\pi\left(x_{m}\right) \xi_{0}\right\|=0 .
$$

Considering a subsequence of $\left\{x_{n}\right\}$, we may assume that

$$
\left\|\pi\left(x_{n}\right) \xi_{0}-\pi\left(x_{n+1}\right) \xi\right\|<2^{-n}, \quad n=1,2, \cdots .
$$

In other words,

$$
\varepsilon\left(\left(x_{n}-x_{n+1}\right) *\left(x_{n}-x_{n+1}\right)\right)(\omega)<4^{-n}, \quad n=1,2, \cdots .
$$

Let $\left\{U_{n}\right\}$ be a decreasing sequence of neighborhoods of $\omega$ in $\Omega$ such that

$$
\varepsilon\left(\left(x_{n}-x_{n+1}\right) *\left(x_{n}-x_{n+1}\right)\right)(\sigma)<4^{-n}
$$

for every $\sigma \in U_{n}, n=1,2, \cdots$. For each $n=1,2, \cdots$, let $e_{n}$ be the projection of $A$ corresponding to the closure of $U_{n}$. Then $e_{n}(\omega)=1$ 
for $n=1,2, \cdots$ Putting $y_{1}=x_{1}$ and $y_{n}=e_{n} x_{n}+\left(1-e_{n}\right) y_{n-1}$ for $n=2,3, \cdots$ by induction,

$$
\begin{gathered}
\varepsilon\left(\left(y_{n}-y_{n+1}\right) *\left(y_{n}-y_{n+1}\right)\right)<4^{-n} ; \\
\pi\left(y_{n}\right) \xi_{0}=\pi\left(x_{n}\right) \xi_{0},
\end{gathered}
$$$$
n=1,2, \cdots \text {. }
$$

Now, for any normal state $\phi$ of $A$, put $\tau_{\varphi}(x)=\phi \circ \varepsilon(x), x \in N$. Then $\tau_{\varphi}$ is a normal finite trace of $N$ with the support $s(\varphi) \in A$, where $s(\varphi)$ means the support of $\varphi$ in $A$. By the inequality:

$$
\tau_{\varphi}\left(\left(y_{n}-y_{n+1}\right) *\left(y_{n}-y_{n+1}\right)\right)=\varphi \circ \varepsilon\left(\left(y_{n}-y_{n+1}\right) *\left(y_{n}-y_{n+1}\right)\right)<4^{-n},
$$

$n=1,2, \cdots,\left\{y_{n} s(\varphi)\right\}$ converges $\sigma$-strongly to $y_{\varphi} \in S_{N}$ because the $\sigma$ strong topology in $S_{N} \cap N s(\varphi)$ is induced by the metric $d$ defined by $d(x, y)=\tau_{\varphi}((x-y) *(x-y))^{1 / 2}, \quad x, y \in S_{N} \cap N s(\varphi)$. Let $\left\{\varphi_{i}\right\}_{i \in I}$ be a maximal family of normal states of $A$ with orthogonal supports. Then $\sum_{i \in I} s\left(\varphi_{i}\right)=1$. Let $y=\sum_{i \in I} y_{\varphi_{i}} \in S_{N}$. Since $\left\{y_{n} s\left(\varphi_{i}\right)\right\}$ converges $\sigma$-strongly to $s\left(\varphi_{i}\right) y=y_{\varphi_{i}}$ for each $i \in I,\left\{y_{n}\right\}$ converges $\sigma$-strongly to $y$. Now we have, by the triangular inequality,

$$
\begin{aligned}
\varepsilon\left(\left(y_{n}-y_{n+p}\right) *\left(y_{n}-y_{n+p}\right)\right)^{1 / 2} & \leqq \sum_{k=n}^{n+p-1} \varepsilon\left(\left(y_{k}-y_{k+1}\right) *\left(y_{k}-y_{k+1}\right)\right)^{1 / 2} \\
& \leqq \sum_{k=n}^{n+p-1} 2^{-k} \leqq 2^{-n+1}
\end{aligned}
$$

for $n, P=1,2, \cdots$. Hence we have

$$
\varepsilon\left(\left(y_{n}-y\right) *\left(y_{n}-y\right)\right)^{1 / 2}=\lim _{p \rightarrow \infty} \varepsilon\left(\left(y_{n}-y_{n+p}\right) *\left(y_{n}-y_{n+p}\right)\right)^{1 / 2} \leqq 2^{-n+1},
$$

so that

$$
\left\|\pi\left(y_{n}\right) \xi_{0}-\pi(y) \xi_{0}\right\|=\varepsilon\left(\left(y_{n}-y\right)^{*}\left(y_{n}-y\right)\right)(\omega)^{1 / 2} \leqq 2^{-n+1} ;
$$

hence

$$
\lim _{n \rightarrow \infty} \pi\left(y_{n}\right) \xi_{0}=\pi(y) \xi_{0} \text {. }
$$

Therefore, the given Cauchy sequence $\left\{\pi\left(x_{n}\right) \xi_{0}\right\}$ in $\pi\left(S_{N}\right) \xi_{0}$ converges to $\pi(y) \xi_{0} \in \pi\left(S_{N}\right) \xi_{0}$. Hence $\pi\left(S_{N}\right) \xi_{0}$ is complete, hence closed in $\mathscr{H}$. This completes the proof.

By [7], we should remind that if $M$ is a von Neumann algebra of type $\mathrm{II}_{1}$ and if $\omega$ is not an isolated point of $\Omega$ then $M / \mathfrak{m}_{\omega}$ does not admit nontrivial representation on a separable Hilbert space even if $M$ does have faithful normal representation on a separable Hilbert space.

Suppose now $A$ is $\sigma$-finite and $\omega$ is not an isolated point of $\Omega$. 
Suppose that any nonzero projection $e \in N$ majorizes a projection $f \in N$ such that $\varepsilon(f)=\varepsilon(e-f)$. Then we claim that the von Neumann algebra $\pi_{\omega}(N)$ does not admit a faithful separable normal representation.

Let $\left\{e_{n}\right\}$ be a decreasing sequence of projections in $A$ converging $\sigma$-strongly to zero such that $e_{n}(\omega)=1$ for $n=1,2, \ldots$. Such a sequence does exist by the nonisolatedness of $\omega$ and the $\sigma$-finiteness of $A$. Let $f_{n}=e_{n}-e_{n+1}$ for $n=1,2, \cdots$. By the assumption for $N$, there exists orthogonal projections $p_{1,1}^{n}$ and $p_{1,2}^{n}$ in $N$ such that $f_{n}=$ $p_{1,1}^{n}+p_{1,2}^{n}$ and $\varepsilon\left(p_{1,1}^{n}\right)=\varepsilon\left(p_{1,2}^{n}\right)=\frac{1}{2} f_{n}$. Suppose we have found projections $\left\{p_{i, j}^{n}: i=1, \cdots, k, j=1,2, \cdots, 2^{i}\right\}$ such that

(1) for fixed $i,\left\{p_{i, j}^{n}: j=1, \cdots, 2^{i}\right\}$ are orthogonal;

(2) $p_{i-1, j}^{n}=p_{i, 2 j-1}^{n}+p_{i, 2 j}^{n}$;

(3) $\varepsilon\left(p_{i, j}^{n}\right)=2^{-i} f_{n}$.

By the assumption for $N$, we can find orthogonal projections $\left\{p_{i+1, j}^{n}\right.$ : $\left.j=1,2, \cdots, 2^{i+1}\right\}$ such that

$$
\begin{aligned}
& p_{i, j}^{n}=p_{i+1,2 j-1}^{n}+p_{i+1,2 j}^{n} ; \\
& \varepsilon\left(p_{i+1, j}^{n}\right)=2^{\tau^{(i+1)}} f_{n}, \quad j=1,2, \cdots, 2^{i+1} .
\end{aligned}
$$

For each integer $i$, put

$$
u_{n, i}=\sum_{j=1}^{2^{n}}(-1)^{j} p_{i, j}^{n} \cdot
$$

Then we have $u_{n, k}^{2}=f_{n}$ and for different $i_{1}$ and $i_{2}, u_{n, i_{1}} u_{n, i_{2}}$ is the difference of two orthogonal projections $p$ and $q$ such that $\varepsilon(p)=$ $\varepsilon(q)=\frac{1}{2} f_{n}$; hence $\varepsilon\left(u_{n, i_{1}} u_{n, i_{2}}\right)=0$ if $i_{1} \neq i_{2}$.

To each real number $s$ we associate a sequence $\left\{i_{s, n}\right\}$ of integers such that

$$
\lim _{n \rightarrow \infty} \frac{i_{s, n}}{2^{n}}=s
$$

If $s \neq t$, there is an $n_{0}$ such that $i_{s, n} \neq i_{t, n}$ for every $n \geqq n_{0}$. Put

$$
u_{s}=\sum_{n=1}^{\infty} u_{n, i_{s, n}} \text {. }
$$

Then we have $\varepsilon\left(u_{s} u_{t}\right)\left(1-e_{n_{0}}\right)=\varepsilon\left(u_{s} u_{t}\right)$. Therefore we have

$$
\tau_{\omega}\left(u_{s}^{2}\right)=1, \tau_{\omega}\left(u_{s} u_{t}\right)=0 \text { if } s \neq t .
$$

Therefore $\left\{\pi\left(u_{s}\right) \xi_{0}\right\}$ is a continuum of orthogonal vectors in $\left[\pi(N) \xi_{0}\right]$. Therefore, the standard representation of the von Neumann algebra $\pi_{\omega}(N)$ is not separable. Thus $\pi_{\omega}(N)$ does not admit a faithful normal separable representation.

Now, let $A$ and $B$ be two abelian von Neumann algebras with 
no minimal projections. Let $C$ be the tensor product $A \otimes B$ of $A$ and $B$. Then $A$ and $B$ are regarded as subalgebras of $C$. If $B$ admits a faithful normal state $\psi$, then there exists a faithful normal projection $\varepsilon$ of norm one of $C$ onto $A$ defined by

$$
\langle\varepsilon(x), \varphi)\rangle=\langle x, \varphi \otimes \psi\rangle
$$

for every $\varphi \in A_{*}$. This map has the property:

$$
\varepsilon(a \otimes b)=\varphi(b) a, a \in A, b \in B \text {. }
$$

If $A$ is $\sigma$-finite, then $C / \mathrm{m}_{\omega}$ is an abelian von Neumann algebra, with no separable faithful normal representation. It is easily seen that the map $\pi_{\omega}$ is $\sigma$-weakly continuous on $B$; hence $\pi_{\omega}(B)$ is a proper von Neumann subalgebra of $C / \mathfrak{m}_{\omega}$ if $B$ has a faithful separable normal representation. Therefore, the pathology that the component algebras are much larger than the synthetic algebra does occur even in the abelian case.

\section{REFERENCES}

1. J. Dixmier Les algèbras d'operateurs dans les espace hilbertién, 2nd. ed., 1969, Gauthier-Villars.

2. J. Feldman, Embedding of $A W^{*}$-algebras, Duke Math. J., 23 (1956), 303-308.

3. - Nonseparability of certain finite factors, Proc. Amer. Math. Soc., 7 (1956), $23-26$.

4. J. Feldman and J. M. G. Fell, Separable representations of rings of operators, Amer. Math. Soc., 65 (1957), 241-249.

5. S. Sakai, The theory of $W^{*}$-algebras, Lecture Notes, Yale Univ., 1962.

6. H. Takemoto, On the homomorphism of von Neumann algebra, Tôhoku Math. J., 21 (1969), 152-157.

7. M. Takesaki, On the nonseparability of singular representations of operator algebra, Kodai, Math. Sem. Rep. 12 (1960), 102-108.

8. F. B. Wright, A reduction for algebras of finite type, Ann. Math. 60 (1954), 560-570.

Received June 8, 1970.

University of California, Los ANgeles, California 



\title{
PACIFIC JOURNAL OF MATHEMATICS
}

\section{EDITORS}

H. SAMELSON

Stanford University

Stanford, California 94305

C. R. HobвY

University of Washington

Seattle, Washington 98105

\section{J. DugunduI}

Department of Mathematics

University of Southern California

Los Angeles, California 90007

RICHARD ARENS

University of California

Los Angeles, California 90024

\section{ASSOCIATE EDITORS}
E. F. BECKENBACH
B. H. Neumann
F. WOLE
K. Yoshida

\section{SUPPORTING INSTITUTIONS}

\author{
UNIVERSITY OF BRITISH COLUMBIA \\ CALIFORNIA INSTITUTE OF TECHNOLOGY \\ UNIVERSITY OF CALIFORNIA \\ MONTANA STATE UNIVERSITY \\ UNIVERSITY OF NEVADA \\ NEW MEXICO STATE UNIVERSITY \\ OREGON STATE UNIVERSITY \\ UNIVERSITY OF OREGON \\ OSAKA UNIVERSITY \\ UNIVERSITY OF SOUTHERN CALIFORNIA
}

\author{
STANFORD UNIVERSITY \\ UNIVERSITY OF TOKYO \\ UNIVERSITY OF UTAH \\ WASHINGTON STATE UNIVERSITY \\ UNIVERSITY OF WASHINGTON

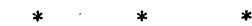 \\ AMERICAN MATHEMATICAL SOCIETY \\ CHEVRON RESEARCH CORPORATION \\ NAVAL WEAPONS CENTER
}

The Supporting Institutions listed above contribute to the cost of publication of this Journal, but they are not owners or publishers and have no responsibility for its content or policies.

Mathematical papers intended for publication in the Pacific Journal of Mathematics should be in typed form or offset-reproduced, (not dittoed), double spaced with large margins. Underline Greek letters in red, German in green, and script in blue. The first paragraph or two must be capable of being used separately as a synopsis of the entire paper. The editorial "we" must not be used in the synopsis, and items of the bibliography should not be cited there unless absolutely necessary, in which case they must be identified by author and Journal, rather than by item number. Manuscripts, in duplicate if possible, may be sent to any one of the four editors. Please classify according to the scheme of Math. Rev. Index to Vol. 39. All other communications to the editors should be addressed to the managing editor, Richard Arens, University of California, Los Angeles, California, 90024.

50 reprints are provided free for each article; additional copies may be obtained at cost in multiples of 50 .

The Pacific Journal of Mathematics is published monthly. Effective with Volume 16 the price per volume (3 numbers) is $\$ 8.00$; single issues, $\$ 3.00$. Special price for current issues to individual faculty members of supporting institutions and to individual members of the American Mathematical Society: $\$ 4.00$ per volume; single issues $\$ 1.50$. Back numbers are available.

Subscriptions, orders for back numbers, and changes of address should be sent to Pacific Journal of Mathematics, 103 Highland Boulevard, Berkeley, California, 94708.

PUBLISHED BY PACIFIC JOURNAL OF MATHEMATICS, A NON-PROFIT CORPORATION

Printed at Kokusai Bunken Insatsusha (International Academic Printing Co., Ltd.), 7-17, Fujimi 2-chome, Chiyoda-ku, Tokyo, Japan. 


\section{Pacific Journal of Mathematics}

\section{Vol. 36, No. $3 \quad$ BadMonth, 1971}

E. M. Alfsen and B. Hirsberg, On dominated extensions in linear subspaces of

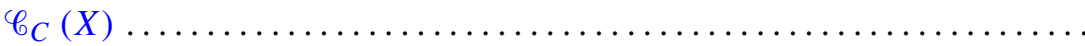

Joby Milo Anthony, Topologies for quotient fields of commutative integral

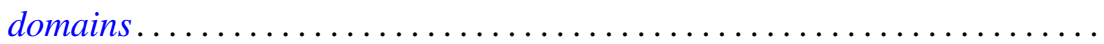

V. Balakrishnan, G. Sankaranarayanan and C. Suyambulingom, Ordered cycle lengths in a random permutation .......................... 603

Victor Allen Belfi, Nontangential homotopy equivalences............... 615

Jane Maxwell Day, Compact semigroups with square roots .............. 623

Norman Henry Eggert, Jr., Quasi regular groups of finite commutative nilpotent algebras .......................................... 631

Paul Erdős and Ernst Gabor Straus, Some number theoretic results ......... 635

George Rudolph Gordh, Jr., Monotone decompositions of irreducible Hausdorff continua .............................................

Darald Joe Hartfiel, The matrix equation $A X B=X \ldots \ldots \ldots \ldots \ldots \ldots . \ldots 69$

James Howard Hedlund, Expansive automorphisms of Banach spaces. II . . . . 671

I. Martin (Irving) Isaacs, The p-parts of character degrees in p-solvable

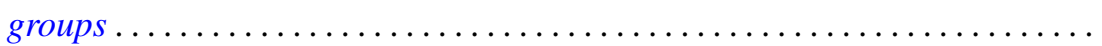

Donald Glen Johnson, Rings of quotients of $\Phi$-algebras ............... 693

Norman Lloyd Johnson, Transition planes constructed from semifield planes....

Anne Bramble Searle Koehler, Quasi-projective and quasi-injective modules.

James J. Kuzmanovich, Completions of Dedekind prime rings as second endomorphism rings...

B. T. Y. Kwee, On generalized translated quasi-Cesàro summability ...

Yves A. Lequain, Differential simplicity and complete integral closure

741

Mordechai Lewin, On nonnegative matrices.

753

Kevin Mor McCrimmon, Speciality of quadratic Jordan algebras ...

Hussain Sayid Nur, Singular perturbations of differential equations in abstract spaces .....................................

D. K. Oates, A non-compact Krein-Milman theorem .

Lavon Barry Page, Operators that commute with a unilateral shift on an invariant subspace...

Helga Schirmer, Properties of fixed point sets on dendrites.

Saharon Shelah, On the number of non-almost isomorphic models of $T$ in a

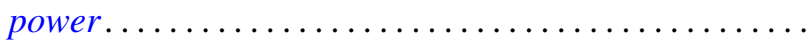

Robert Moffatt Stephenson Jr., Minimal first countable Hausdorff spaces....

Masamichi Takesaki, The quotient algebra of a finite von Neumann algebra 